\title{
Lymphopenia is an important prognostic factor in peripheral T-cell lymphoma (NOS) treated with anthracycline-containing chemotherapy
}

Yu Ri Kim, Jin Seok Kim, Soo Jeong Kim, Hyun Ae Jung², Seok Jin Kim², Won Seog Kim², Hye Won Lee², Hyeon Seok Eom ${ }^{3}$, Seong Hyun Jeong ${ }^{4}$, Joon Seong Park ${ }^{4}$ June-Won Cheong ${ }^{1}$ and Yoo Hong Min

\begin{abstract}
Background: Peripheral T-cell lymphoma, not otherwise specified (PTCL-NOS) is a heterogeneous group of aggressive T-cell lymphomas with poor treatment outcomes. The aim of this study was to evaluate whether lymphopenia at diagnosis would have an adverse effect on survival in patients with PTCL-NOS treated with anthracycline-containing chemotherapy.
\end{abstract}

Methods: A total of 118 patients with PTCL-NOS treated with anthracycline-containing chemotherapy from 4 Korean institutions were included.

Results: Thirty-six patients (30.5\%) had a low absolute lymphocyte count (ALC, $<1.0 \times 10^{9} / \mathrm{L}$ ) at diagnosis. Patients with lymphopenia had shorter overall survival (OS) and progression-free survival (PFS) rates compared with patients with high ALCs $(P=0.003, P=0.012$, respectively). In multivariate analysis, high-intermediate/high-risk International Prognostic Index (IPI) scores and lymphopenia were both associated with shorter OS and PFS. Treatment-related mortality was $25.0 \%$ in the low ALC group and $4.8 \%$ in the high ALC group $(P=0.003)$. In patients considered high-intermediate/high-risk based on IPI scores, lymphopenia was also associated with shorter OS and PFS ( $P=$ $0.002, P=0.001$, respectively).

Conclusion: This study suggests that lymphopenia could be an independent prognostic marker to predict unfavorable OS and PFS in patients with PTCL-NOS treated with anthracycline-containing chemotherapy and can be used to further stratify high-risk patients using IPI scores.

Keywords: peripheral T-cell lymphoma, not otherwise specified, lymphopenia, international prognostic index, prognostic factor

\section{Background}

Peripheral T-cell lymphomas (PTCL) account for approximately $12 \%$ to $15 \%$ of all non-Hodgkin's lymphomas in Western countries and $15 \%$ to $20 \%$ in Asian countries [1,2]. Peripheral T-cell lymphoma, not otherwise specified (PTCL-NOS), is the most common heterogeneous subgroup of PTCL because it includes lymphomas with no definitive clinical or biologic profile and it cannot be classified into a specific subtype [3]. PTCL-NOS is a highly aggressive lymphoma with a poor response to

\footnotetext{
* Correspondence: hemakim@yuhs.ac

'Division of Hematology, Department of Internal Medicine, Yonsei University College of Medicine, Seoul, 120-752, Korea

Full list of author information is available at the end of the article
}

conventional chemotherapy and a 5-year overall survival (OS) of about $25 \%$ to $45 \%$ [4]. Anthracycline-containing chemotherapy, such as CHOP (cyclophosphamide, doxorubicin, vincristine and prednisone) or CHOP-like regimens, are considered to be standard therapy for PTCL-NOS, although remission rates are less than satisfactory [1]. More intensive regimens, such as hyperCVAD (hyperfractionated cyclophosphamide, vincristine, doxorubicin, and dexamethasone) and hyper-CHOP, have not shown improved outcomes compared with CHOP regimens [5]. Several prognostic factors, including the International Prognostic Index (IPI), Prognostic Index for T-cell lymphoma (PIT), and International Peripheral T-cell Lymphoma Project (IPTCLP), have been 
suggested as methods to determine prognostic factors for outcomes with PTCL-NOS [6-9]. In addition, biologic markers such as nuclear factor (NF) $\kappa \mathrm{B}$ and cytochrome P4503A4 isoenzymes have been proposed; however, they do not stratify PTCL-NOS completely [3,10-12]. As a result, there is no single or simple clinical or biologic parameter for predicting treatment outcomes, except for IPI, in patients with PTCL-NOS. Because previous prognostic markers, such as IPI, have been based on information from all patients with PTCL-NOS regardless of chemotherapy regimen used, the role of IPI needs to be evaluated in patients treated with similar chemotherapy regimens. This would allow for identification of additional simple prognostic markers in the same population of patients.

Lymphopenia measured by absolute lymphocyte count (ALC) at diagnosis has been studied as an independent prognostic factor for poor survival in many hematologic malignancies, including Hodgkin's disease, diffuse large B-cell lymphoma (DLBCL), and follicular lymphoma [13-19]. In addition, it is known as a poor prognostic marker in solid tumors such as metastatic breast cancer and sarcomas [18]. Lymphopenia can also be used as a predictable marker for the relapse after chemotherapy; lymphocyte recovery after chemotherapy and autologous hematopoietic stem cell transplantation (ASCT) can help predict clinical outcomes in DLBCL patients $[20,21]$. A few studies have reported the clinical impact of lymphopenia in T-cell lymphoma. Recently, the role of lymphopenia at diagnosis was suggested as a powerful predictor of unfavorable treatment outcomes in extranodal natural killer/T-cell lymphoma (ENKL) [22]. Because there is no information on the role of lymphopenia at diagnosis of PTCL-NOS, we evaluated its prognostic value in the patients with PTCL-NOS treated with similar chemotherapy regimens. The objective of this study was to retrospectively investigate whether lymphopenia is a predictive marker for survival in patients with PTCL-NOS treated with anthracycline-containing chemotherapy.

\section{Patients and methods \\ Patients}

Patients diagnosed with PTCL between January 2000 and December 2009 from 4 Korean institutions were evaluated for inclusion into the study. Patients with a diagnosis of PTCL other than PTCL-NOS, such as anaplastic large cell lymphoma, angioimmunoblastic T-cell lymphoma, enteropathy-associated T-cell lymphoma, ENKL, subcutaneous panniculitis-like T-cell lymphoma, primary cutaneous T-cell lymphoma (e.g., mycosis fungoides) were excluded. Specific extranodal presentations of PTCL-NOS including primary central nervous system (CNS) lymphoma or primary cutaneous lymphoma were also excluded. Among 169 patients with PTCL-NOS screened, 21 were excluded for the following reasons: 2 patients for double primary cancer, 5 for up-front ASCT, 4 for primary CNS lymphoma, 5 for primary cutaneous lymphoma, and 5 for incomplete clinical data. Another 15 (8.9\%) patients who did not receive chemotherapy because of poor performance status, combined comorbidity, or patient refusal were also excluded. A total of 133 patients received systemic chemotherapy. Of these, $118(88.7 \%)$ patients were treated with anthracycline-containing chemotherapy (e.g., CHOP or CHOPlike regimens) as first-line treatment and 15 (11.3\%) were treated without anthracycline-containing chemotherapy (e.g., IMEP [ifosfamide, etoposide, methotrexate, prednisone]). Therefore, 118 patients were included in the trial.

Medical records were retrospectively reviewed for patient demographics. These included age ( $<60$ vs. $\geq 60$ years), gender (male vs. female), Eastern Cooperative Oncology Group (ECOG) performance status (0-1 vs. 2-4), the presence of B symptom (present vs. absent), Ann Arbor stage (1-2 vs. 3-4), the number of extranodal sites involved (0-1 vs. $\geq 2$ ), bone marrow involvement (positive vs. negative), lactic dehydrogenase (LDH) concentrations (normal vs. elevated), $\operatorname{ALC}\left(\geq 1.0 \times 10^{9} / \mathrm{L}\right.$ vs. $\left.<1.0 \times 10^{9} / \mathrm{L}\right)$, and prognostic scores such as IPI (low risk/low-intermediate risk vs. high-intermediate/high risk) and PIT (group 1-2 vs. group 3-4). For this study, lymphopenia was defined as an ALC less than $1.0 \times 10^{9} / \mathrm{L}$. Complete blood counts $(\mathrm{CBC})$ with differential and chemistry were performed at the time of diagnosis and prior to treatment. No patients showed clinical signs of severe infection at the time of laboratory testing. The study protocol was approved by the institutional review board from each participating institution.

\section{Prognostic scores}

IPI scores were based on age, ECOG performance status, LDH concentrations, the number of extranodal sites involved, and Ann Arbor stage as described above [9]. Four risk groups were defined by IPI score: 0 to 1 , low risk; 2, low-intermediate risk; 3 , high-intermediate risk; and 4 to 5 , high risk. PIT scores were calculated using age, ECOG performance status, LDH, and bone marrow involvement as described above. Four risk groups were defined by PIT scores: 0 , group $1 ; 1$, group $2 ; 2$, group 3 ; and 3 to 4 , group 4 [6].

\section{Treatment and response}

Anthracycline-containing chemotherapy included CHOP ( $\mathrm{n}=98)$, CHOP-like regimens $(\mathrm{n}=14)$, ProMACE/CytaBOM (prednisone, cyclophosphamide, doxorubicin, etoposide, cytarabine, bleomycin, vincristine, and methotrexate; $\mathrm{n}=2$ ), CAVOP (cyclophosphamide, doxorubicin, etoposide, vincristine, and prednisolone; $\mathrm{n}=2$ ), or hyper-CVAD 
$(\mathrm{n}=2)$. Tumor response was defined as a complete response (CR), partial response (PR), stable disease, and progressive disease according to the International Workshop criteria [23]. Overall response rate (ORR) was defined as the proportion of patients achieving a PR or better.

\section{Statistical methods}

The significance for categorical variables was calculated using the chi-square test. Continuous variables were compared by the t-test. Overall survival (OS) was measured from the first date of diagnosis until death from any cause, with surviving patients censored at the last follow-up date. Progression-free survival (PFS) was defined as the time from the date of diagnosis until disease progression, relapse after response, or death due to lymphoma or treatment. Death from other causes or survival at last followup were censored. Survival curves were plotted by the Kaplan-Meier method and compared using the log-rank test. The influence of each prognostic factor identified by univariate analysis was assessed by multivariate analysis using Cox proportional-hazards regression stepwise method. A $P$-value $<0.05$ was considered statistically significant for all analyses. All statistical analyses were performed using SPSS for Windows, Version 18.0.

\section{Results}

\section{Patient characteristics}

A total of 118 patients were treated with anthracyclinecontaining chemotherapy. The study group consisted of 79 males $(66.9 \%)$ and 39 females $(33.0 \%)$ with a median age of 56 years (range, 20-86 years). Fourteen (11.8\%) patients presented with a poor performance status, and 32 (27.1\%) had B symptoms at diagnosis. Seventy-nine (66.9\%) patients had stage III or IV advanced disease. The number of patients with extranodal involvement at more than 1 sites and involvement of bone marrow were 35 (29.6\%) and 33 (27.9\%), respectively. Sixty-one (51.6\%) patients had elevated LDH. For IPI scores, 44 (37.3\%) patients were classified as low risk, 31 (26.3\%) as lowintermediate risk, 30 (25.4\%) as high-intermediate risk, and $13(11.0 \%)$ as high risk. For PIT scores, 30 (25.4\%) patients were classified in group 1, $43(36.4 \%)$ in group 2, $28(23.7 \%)$ in group 3, and $17(14.4 \%)$ in group 4.

\section{Clinical characteristics according to absolute lymphocyte count}

The median ALC was $1.32 \times 10^{9} / \mathrm{L}$ (range, 0.039-5.03 $\times$ $\left.10^{9} / \mathrm{L}\right)$. Patients were divided into 2 groups according to ALC $\left(\geq\right.$ or $\left.<1.0 \times 10^{9} / \mathrm{L}\right)$. The proportion of patients with a low ALC was 30.5\% (36 of 118 patients). For patients classified as having a high ALC $(n=82)$, the median level was $1.78 \times 10^{9} / \mathrm{L}$ (range, 1.04-5.03 $\times 10^{9} / \mathrm{L}$ ). Patients with low ALC $(\mathrm{n}=36)$ had a median level of $0.69 \times 10^{9} / \mathrm{L}$ (range, $0.039-0.98 \times 10^{9} / \mathrm{L}$ ). The clinical characteristics of patients according to ALC are shown in Table 1. The following characteristics were similar between the 2 groups: age, gender, performance status, presence of B symptom, Ann Arbor stage, number of extranodal sites involved, and involvement of bone marrow. The average number of cycles of first-line chemotherapy given was lower in low ALC group compared with the high ALC group $(P=0.007)$. Elevated LDH, high-intermediate/high risk IPI scores and high PIT scores were correlated with a low ALC $(P=0.031, P=$ $0.043, P=0.010$, respectively).

\section{Response according to absolute lymphocyte count}

Among the 118 patients who were treated with anthracycline-containing chemotherapy, 105 were evaluable for treatment response. Fifty-six (47.4\%) patients achieved a CR and 78 (66.1\%) achieved a PR or better. The CR rate

Table 1 Patient characteristics according to absolute lymphocyte count

\begin{tabular}{|c|c|c|c|}
\hline & $\begin{array}{l}\text { High ALC } \\
(N=82)\end{array}$ & $\begin{array}{l}\text { Low ALC } \\
(N=36)\end{array}$ & $P$-value \\
\hline \multicolumn{4}{|l|}{ Age } \\
\hline$<60$ vs. $\geq 60$ years & $51 / 31$ & $21 / 15$ & 0.692 \\
\hline \multicolumn{4}{|l|}{ Gender } \\
\hline Male vs. Female & $55 / 27$ & $24 / 12$ & 0.966 \\
\hline \multicolumn{4}{|l|}{ Performance status } \\
\hline $0-1$ vs. $2-4$ & $74 / 8$ & $30 / 6$ & 0.355 \\
\hline \multicolumn{4}{|l|}{ B symptom } \\
\hline Present vs. Absent & $21 / 61$ & $11 / 25$ & 0.578 \\
\hline \multicolumn{4}{|l|}{ Stage } \\
\hline $1-2$ vs. $3-4$ & $31 / 51$ & $8 / 28$ & 0.098 \\
\hline \multicolumn{4}{|l|}{ Extranodal involvement } \\
\hline $0-1$ vs. $\geq 2$ & $62 / 20$ & $21 / 15$ & 0.059 \\
\hline \multicolumn{4}{|l|}{ Bone marrow involvement } \\
\hline Positive vs. Negative & $21 / 61$ & $12 / 24$ & 0.389 \\
\hline \multicolumn{4}{|l|}{ LDH } \\
\hline Normal vs. Elevated & $45 / 37$ & $12 / 24$ & 0.031 \\
\hline \multicolumn{4}{|l|}{$\mid \mathrm{PI}$} \\
\hline L, LI vs. HI, H & $57 / 25$ & 18/18 & 0.043 \\
\hline \multicolumn{4}{|l|}{ PIT } \\
\hline Group 1-2 vs. 3-4 & $57 / 25$ & $16 / 20$ & 0.010 \\
\hline \multicolumn{4}{|l|}{ CR } \\
\hline CR vs. non-CR & $42 / 37$ & $14 / 12$ & 0.952 \\
\hline \multicolumn{4}{|l|}{ Response ( $\geq$ PR) } \\
\hline Responder vs. Non-responder & $61 / 18$ & $17 / 9$ & 0.231 \\
\hline \multicolumn{4}{|l|}{ TRM during the $1^{\text {st }}$ line chemotherapy } \\
\hline Yes vs. No & $4 / 78$ & $9 / 27$ & 0.003 \\
\hline \multicolumn{4}{|l|}{ Cycles of $1^{\text {st }}$ line Chemotherapy } \\
\hline Median, range & $6(1-8)$ & $3(1-9)$ & 0.007 \\
\hline
\end{tabular}

$\mathrm{LDH}$, lactate dehydrogenase; IPI, International Prognostic Index; L, low; LI, lowintermediate; $\mathrm{HI}$, high-intermediate; $\mathrm{H}$, high; PIT, Prognostic Index for peripheral T-cell lymphoma; CR, complete response; PR, partial response; TRM, treatment related mortality; ALC, absolute lymphocyte count. 
was $53.2 \%$ (42 of 79 patients) and the ORR was $78.2 \%$ (61 of 79 patients) in the high ALC group. For the low ALC group, the CR rate was $53.8 \%$ (14 of 26 patients) and the ORR was $65.4 \%$ (17 of 26 patients). There were no statistically significant differences in the CR rate and ORR based on ALC (Table 1).

\section{Overall survival and progression-free survival analysis}

The median duration of follow-up was 27.6 months (range, 1.0-69.2 months). Sixty (50.8\%) patients died during the follow-up period. The rate of treatment-related mortality (TRM) during first-line anthracycline-containing chemotherapy was $11.0 \%$ (13 of 118 patients); $25.0 \%$ (9 of 36 patients) in low ALC group and 4.8\% (4 of 82 patients) in high ALC group $(P=0.003)$. The 3 -year estimate for OS was $48.5 \%$ and PFS was $35.0 \%$.

The median OS was longer in patients with high ALCs compared to those with low ALCs (69.4 months vs. 15.5 months, $P=0.003$; Figure $1 \mathrm{~A}$ ). In univariate analysis, the following variables were associated with an unfavorable OS: poor performance status $(P<0.001)$, number of extranodal sites involved $\geq 2(P=0.005)$, elevated LDH $(P<0.001)$, high-intermediate/high risk IPI $(P<0.001)$, and PIT groups $3,4(P<0.001$; Table 2$)$. In multivariate analysis, IPI (hazard ratio [HR] 4.06, 95\% CI 2.40-6.84, $P<0.001$ ) and lymphopenia (HR 2.24, 95\% CI $1.33-3.78, P=0.002)$ were independent prognostic factors for predicting OS in patients with PTCL-NOS (Table 3).
The median PFS was longer in patients with high ALCs compared to those with low ALCs (18.1 months vs. 7.0 months, $P=0.012$; Figure $1 \mathrm{~B})$. Poor performance status $(P=0.016)$, advanced stage $(P=0.041)$, number of extranodal sites involved $\geq 2(P=0.003)$, bone marrow involvement $(P=0.039)$, elevated LDH $(P=0.025)$, high IPI scores $(P<0.001)$, and high PIT scores $(P=0.026)$ were associated with a shorter PFS by univariate analysis. Of these factors, high IPI scores (HR 2.43, 95\% CI 1.51-3.90, $P<0.001)$ and lymphopenia (HR 1.94, 95\% CI 1.19-3.18, $P=0.008$ ) were significant independent prognostic factors for predicting PFS by multivariate analysis (Table 3 ).

\section{Survival analysis of high-intermediate/high-risk IPI patients}

Forty-three $(36.4 \%)$ patients were categorized as highintermediate/high risk by IPI scores. The median followup duration was 8.1 months (range, 4.3-11.8 months). Eighteen (41.9\%) patients were in the low ALC group. Thirty-three patients (76.7\%) died during the follow-up period. The TRM rate during first-line anthracyclinecontaining chemotherapy was $4.0 \%$ ( 1 of 25 patients) in the high ALC group and $38.8 \%$ (7 of 18 patients) in the low ALC group $(P=0.006)$. The 3 -year estimate for OS was $20.1 \%$ and for PFS was $17.9 \%$. The median OS was longer in patients in the high ALC group-10.6 months (range, 3.9-17.2 months) versus 4.0 months (range, 1.1-6.8 months) in the low ALC group $(P=0.002)$. Lymphopenia was also independently associated with an unfavorable
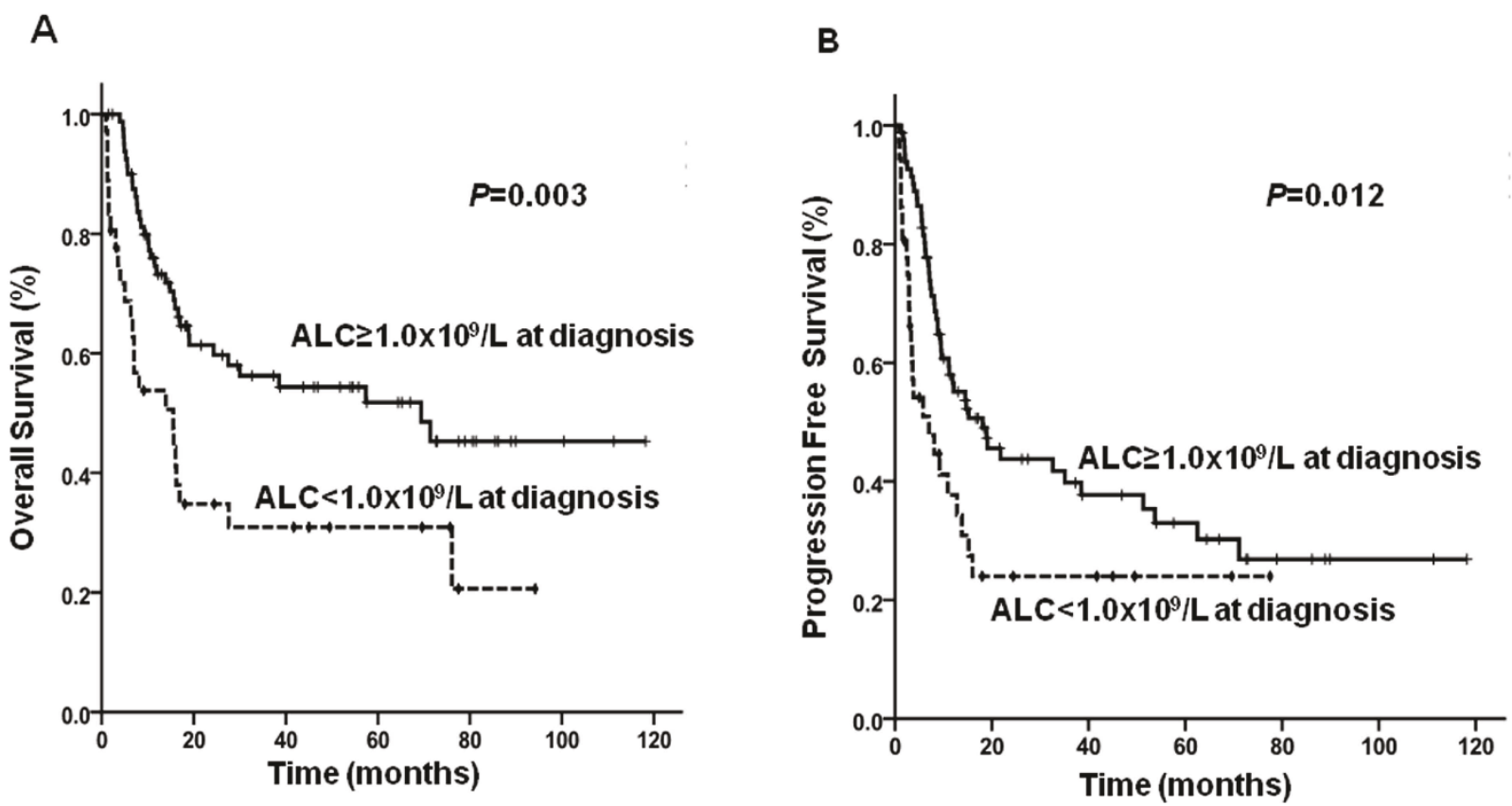

Figure 1 Overall survival $(A, P=0.003)$ and progression free survival $(B, P=0.012)$ according to absolute lymphocyte count $(A L C)$. 
Table 2 Univariate analysis for overall survival and progression free survival in patients with PTCL-NOS

\begin{tabular}{|c|c|c|c|c|c|c|}
\hline & Median OS, months & HR $(95 \% \mathrm{Cl})$ & $P$-value & Median PFS, months & HR $(95 \% \mathrm{Cl})$ & $P$-value \\
\hline \multicolumn{7}{|l|}{ Age } \\
\hline$<60$ years & 69.4 & $1.54(0.92-2.58)$ & 0.100 & 11.9 & $1.00(0.62-1.62)$ & 0.976 \\
\hline$\geq 60$ years & 18.9 & & & 13.8 & & \\
\hline \multicolumn{7}{|l|}{ Gender } \\
\hline Male & 30.0 & $1.24(0.73-2.11)$ & 0.422 & 12.1. & $0.91(0.55-1.51)$ & 0.732 \\
\hline Female & 27.5 & & & 15.2 & & \\
\hline \multicolumn{7}{|l|}{ Performance status } \\
\hline $0-1$ & 57.4 & $4.09(2.10-8.00)$ & $<0.001$ & 14.5 & $2.28(1.16-4.46)$ & 0.016 \\
\hline $2-4$ & 6.3 & & & 3.6 & & \\
\hline \multicolumn{7}{|l|}{ B symptom } \\
\hline Absent & 38.5 & $1.45(0.84-2.50)$ & 0.178 & 14.7 & $1.31(0.79-2.16)$ & 0.282 \\
\hline Present & 15.6 & & & 7.1 & & \\
\hline \multicolumn{7}{|l|}{ Stage } \\
\hline $1-2$ & 69.4 & $1.63(0.93-2.87)$ & 0.086 & 19.1 & $1.68(1.02-2.77)$ & 0.041 \\
\hline $3-4$ & 16.6 & & & 9.5 & & \\
\hline \multicolumn{7}{|c|}{ Extranodal involvement } \\
\hline $0-1$ & 69.4 & $2.10(1.24-3.54)$ & 0.005 & 18.1 & $2.08(1.29-3.35)$ & 0.003 \\
\hline$\geq 2$ & 11.5 & & & 8.1 & & \\
\hline \multicolumn{7}{|c|}{ Bone marrow involvement } \\
\hline Negative & 57.4 & $1.62(0.93-2.79)$ & 0.084 & 14.5 & $1.68(1.02-2.76)$ & 0.039 \\
\hline Positive & 10.2 & & & 7.3 & & \\
\hline \multicolumn{7}{|l|}{$\mathrm{LDH}$} \\
\hline Normal & NR & $2.89(1.67-5.00)$ & $<0.001$ & 16.0 & $1.69(1.06-2.68)$ & 0.025 \\
\hline Elevated & 11.5 & & & 8.8 & & \\
\hline \multicolumn{7}{|l|}{$\mid \mathrm{PI}$} \\
\hline L, LI & NR & $3.96(2.36-6.66)$ & $<0.001$ & 18.1 & $2.34(1.47-3.74)$ & $<0.001$ \\
\hline $\mathrm{HI}, \mathrm{H}$ & 8.1 & & & 8.1 & & \\
\hline \multicolumn{7}{|l|}{ PIT } \\
\hline Group 1-2 & 76.1 & $2.78(1.67-4.62)$ & $<0.001$ & 15.2 & $1.69(1.06-2.69)$ & 0.026 \\
\hline Group 3-4 & 10.1 & & & 9.4 & & \\
\hline \multicolumn{7}{|l|}{$\mathrm{ALC}$} \\
\hline$\geq 1.0 \times 10^{9} / /$ & 69.4 & $2.19(1.30-3.67)$ & 0.003 & 18.1 & $3.01(1.14-3.02)$ & 0.012 \\
\hline$<1.0 \times 10^{9} / /$ & 15.5 & & & 7.0 & & \\
\hline
\end{tabular}

LDH, lactate dehydrogenase; IPI, International Prognostic Index; L, low; LI, low-intermediate; HI, high-intermediate; H, high; PIT, Prognostic Index for peripheral Tcell lymphoma; ALC, absolute lymphocyte count; NR, not reached; OS, overall survival; PFS, progression free survival.

impact on OS (HR 3.09, 95\% CI 1.52-6.32, $P=0.002)$ and PFS (HR 4.01, 95\% CI 1.80-9.00, $P=0.001$; Figures $2 \mathrm{~A}$ and $2 \mathrm{~B})$. No other variables were significantly associated with OS or PFS by univariate analysis (Table 4).

\section{Discussion}

This study found that lymphopenia is an unfavorable prognostic factor for patients with PTCL-NOS treated with anthracycline-containing chemotherapy. Higher IPI

Table 3 Multivariate analysis for overall survival and progression free survival in patients with PTCL- NOS

\begin{tabular}{|c|c|c|c|c|}
\hline & $\begin{array}{l}\text { OS } \\
P \text {-value }\end{array}$ & HR $(95 \% \mathrm{Cl})$ & $\begin{array}{l}\text { PFS } \\
P \text {-value }\end{array}$ & HR $(95 \% \mathrm{Cl})$ \\
\hline \multicolumn{5}{|l|}{$\mid \mathrm{PI}$} \\
\hline L, LI & $<0.001$ & $4.06(95 \%$ Cl 2.40-6.84) & $<0.001$ & $2.43(95 \%$ Cl 1.51-3.90) \\
\hline \multicolumn{5}{|l|}{$\mathrm{HI}, \mathrm{H}$} \\
\hline \multicolumn{5}{|l|}{$\mathrm{ALC}$} \\
\hline$\geq 1.0 \times 10^{9} / 1$ & 0.002 & $2.24(95 \%$ Cl 1.33-3.78) & 0.008 & $1.94(95 \%$ Cl 1.19-3.18) \\
\hline$<1.0 \times 10^{9} / 1$ & & & & \\
\hline
\end{tabular}

IPI, International Prognostic Index; L, low; LI, low-intermediate; HI, high-intermediate; H, high; ALC, absolute lymphocyte count; OS, overall survival; PFS, progression free survival. 

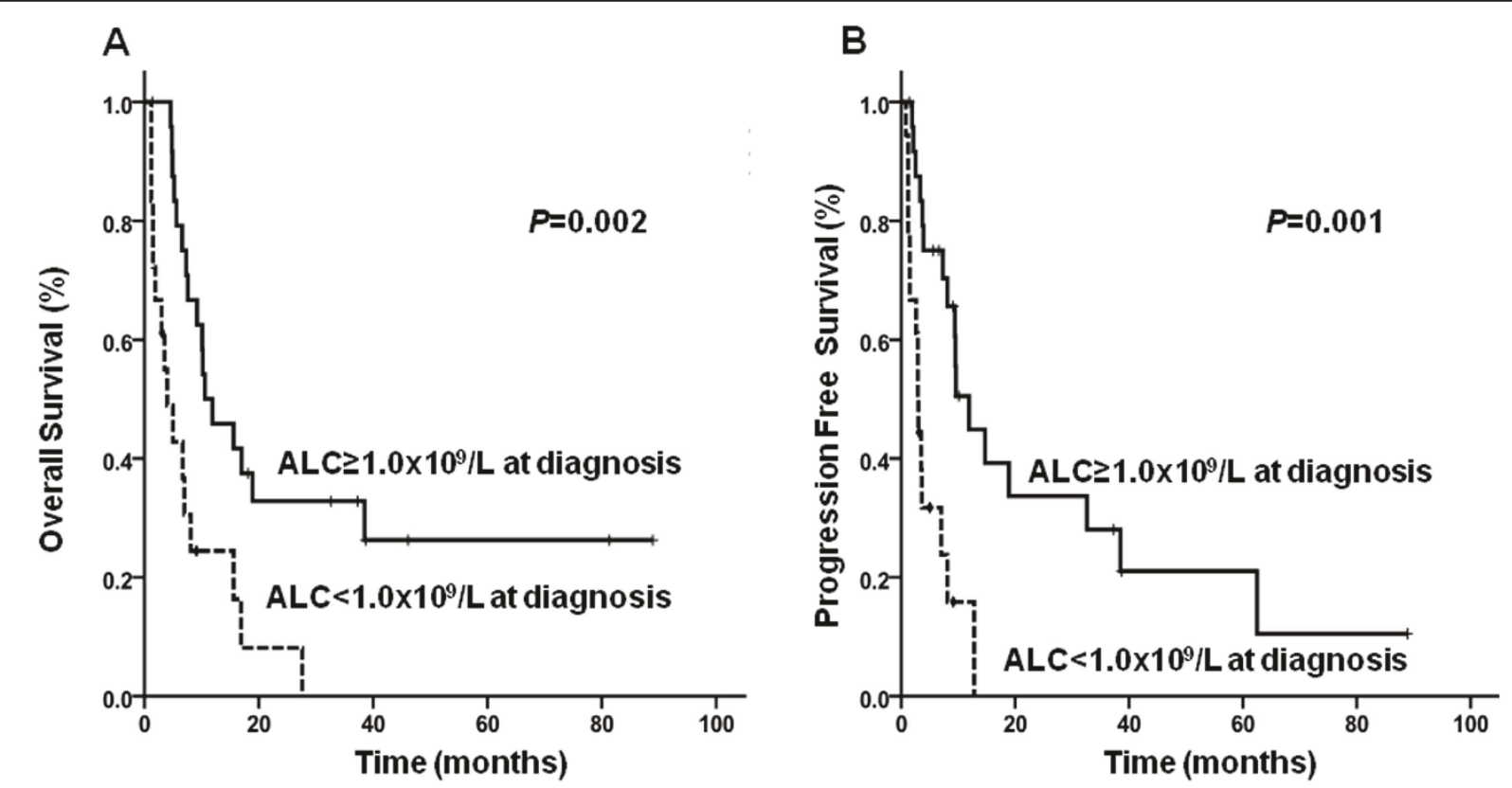

Figure 2 Overall survival $(A, P=0.002)$ and progression free survival $(B, P=0.001)$ according to absolute lymphocyte count $(A L C)$ in PTCL, NOS patients with high-intermediate/high risk IPI.

scores and lymphopenia prior to chemotherapy were independent prognostic factors for shorter OS and PFS in these patients. Lymphopenia was frequently observed in patients with elevated LDH, high-intermediate/high risk IPI scores, and high PIT scores $(P=0.031, P=$ $0.043, P=0.010$, respectively). However, lymphopenia had a significant role in identifying subgroups with a poorer prognosis among patients at high-risk according to IPI scores; in these patients, lymphopenia was associated with significantly shorter OS and PFS $(P=0.003$, $P=0.012$, respectively).

Both IPI and PIT scores have been used as important prognostic factors in PTCL [6,9]. Recently, IPI scores were found to be the most reliable factor in predicting survival, but PIT scores had no significant prognostic role according to the IPTCLP [24]. However, the prognostic value of both these factors were studied regardless of the type of systemic chemotherapy. Moreover, no parameters were used to predict treatment outcomes or further stratify patients with the same IPI scores. Castillo et al. reported that a PIT score $>2$ and lymphopenia were independent prognostic factors for predicting a poor response to therapy and survival in 69 patients with PTCL-NOS [25]. However, this study included only 37 patients who were treated with systemic chemotherapy [25]. Therefore, there was insufficient evidence to determine the prognostic role of lymphopenia in PTCL-NOS. According to our data, 53.3\% (8 of 15) of untreated patients did not receive chemotherapy because of poor performance status, and $60.0 \%$ (9 of 15) of these patients had lymphopenia at diagnosis. Poor performance status and lymphopenia might be frequently observed in patients who do not receive chemotherapy. Therefore, any analysis of the prognostic role of lymphopenia should be performed only among patients who receive similar systemic chemotherapy. In our study, we enrolled patients newly diagnosed with PTCL-NOS who were treated with anthracycline-containing chemotherapy as first-line treatment and excluded patients who did not receive any treatment or who received up-front ASCT. Therefore, patients enrolled in our study may be more homogenous compared with patients from previous studies and may be more appropriate for evaluating prognostic factors.

The causes for lymphopenia are multi-factorial and its consequences are heterogeneous. First of all, lymphopenia could be related to inflammation, a condition usually accompanied by relative neutrophilia or absolute lymphopenia. In certain situations, inflammatory mediators seem to play an important role in the development and progression of cancers [26]. There are some reports on the relationship between inflammation and cancer treatment outcomes via the transcription factors NF- $\kappa$ B in PTCL $[11,27]$. In our study, lymphopenia was not simply a result of impairment of bone marrow function, because there was no significant difference in bone marrow involvement between ALC groups $(P=0.578)$. It could be suggested that lymphopenia may be related to higher tumor burden and increased inflammatory mediators because we found that lymphopenia was closely related to elevated LDH, 
Table 4 Univariate analysis for overall survival and progression free survival in high-intermediate and high risk IPI patients

\begin{tabular}{|c|c|c|c|c|c|c|}
\hline & Median OS, months & HR $(95 \% \mathrm{Cl})$ & $P$-value & Median PFS, months & HR $(95 \% \mathrm{Cl})$ & $P$-value \\
\hline \multicolumn{7}{|l|}{ Age } \\
\hline$<60$ years & 7.0 & $0.79(0.39-1.61)$ & 0.512 & 2.9 & $0.50(0.24-1.01)$ & 0.059 \\
\hline$\geq 60$ years & 9.2 & & & 9.6 & & \\
\hline \multicolumn{7}{|l|}{ Gender } \\
\hline Male & 10.1 & $1.33(0.64-2.76)$ & 0.444 & 8.1 & $1.07(0.29-2.29)$ & 0.862 \\
\hline Female & 5.2 & & & 3.5 & & \\
\hline \multicolumn{7}{|l|}{ Performance status } \\
\hline $0-1$ & 10.1 & $1.72(0.79-3.73)$ & 0.168 & 8.1 & $1.15(0.51-2.59)$ & 0.728 \\
\hline $2-4$ & 4.8 & & & 3.6 & & \\
\hline \multicolumn{7}{|l|}{ B symptom } \\
\hline Absent & 9.2 & $1.29(0.62-2.66)$ & 0.490 & 8.1 & $1.09(0.51-2.33)$ & 0.810 \\
\hline Present & 7.0 & & & 3.6 & & \\
\hline \multicolumn{7}{|l|}{ Stage } \\
\hline $1-2$ & 4.0 & $0.21(0.02-0.72)$ & 0.147 & 3.6 & $0.45(0.05-3.44)$ & 0.445 \\
\hline $3-4$ & 9.2 & & & 8.1 & & \\
\hline \multicolumn{7}{|c|}{ Extranodal involvement } \\
\hline $0-1$ & 10.1 & $1.13(0.56-2.28)$ & 0.729 & 14.7 & $1.27(0.61-2.67)$ & 0.518 \\
\hline$\geq 2$ & 8.1 & & & 3.9 & & \\
\hline \multicolumn{7}{|c|}{ Bone marrow involvement } \\
\hline Negative & 11.9 & $1.33(0.66-2.67)$ & 0.414 & 9.5 & $1.29(0.64-2.61)$ & 0.467 \\
\hline Positive & 7.3 & & & 7.0 & & \\
\hline \multicolumn{7}{|l|}{ LDH } \\
\hline Normal & 9.2 & $1.51(0.45-4.97)$ & 0.498 & 8.1 & $1.54(0.46-5.10)$ & 0.474 \\
\hline Elevated & 7.6 & & & 7.3 & & \\
\hline \multicolumn{7}{|l|}{ PIT } \\
\hline Group 1-2 & 16.9 & $1.35(0.58-3.14)$ & 0.476 & 8.1 & $1.06(0.45-2.48)$ & 0.883 \\
\hline Group 3-4 & 7.6 & & & 7.3 & & \\
\hline \multicolumn{7}{|l|}{$\mathrm{ALC}$} \\
\hline$\geq 1.0 \times 10^{9} / /$ & 10.6 & $3.09(1.52-6.32)$ & 0.002 & 11.9 & $4.02(1.80-8.97)$ & 0.001 \\
\hline$<1.0 \times 10^{9} / /$ & 4.0 & & & 2.9 & & \\
\hline
\end{tabular}

LDH, lactate dehydrogenase; IPI, International Prognostic Index; L, low; LI, low-intermediate; HI, high-intermediate; H, high; PIT, Prognostic Index for peripheral Tcell lymphoma; ALC, absolute lymphocyte count; OS, overall survival; PFS, progression free survival.

high-intermediate/high risk IPI scores, and high PIT scores. However, there may be other clinical meanings of lymphopenia besides tumor burden, since lymphopenia was an independent prognostic factor even among patients classified as high-intermediate/high risk based on IPI scores.

ALC is a surrogate marker of host immunity. Because lymphopenia is reflective of a damaged immune system, patients with lymphopenia usually showed poor response and survival rates [25]. Previous studies have explained why low ALCs might be related to immune suppression or be a consequence of lymphocytic cytokines produced by lymphoma cells [18]. Plonquet et al. reported that a low NK cell count was related to a poor response to chemotherapy in patients with DLBCL treated with rituximab [28]. CD4 lymphopenia is known to be an independent risk factor for febrile neutropenia and early death in cancer patients receiving cytotoxic chemotherapy [29]. Therefore, lymphopenia may increase a patient's vulnerability to infection during chemotherapy. Infection-related mortality is a main cause of death during the chemotherapy for lymphoma. In our study, TRM during first-line anthracycline-containing chemotherapy was significantly higher in patients with low ALCs compared to those with high ALCs $(25.0 \%$ vs. $4.8 \%, P=0.003)$, even though there was no difference in the treatment response rates between the 2 groups $(P=$ $0.154)$. Therefore, survival differences according to the ALC are not associated with a poor response to chemotherapy, but rather to a high rate of early mortality during the chemotherapy. In conclusion, chemotherapy regimens should be carefully selected for patients with PTCL-NOS and lymphopenia in order to reduce TRM during first-line chemotherapy. Newly developed targeted agents or cellular therapy for treatment of these patients should be considered in the future. 
Furthermore, lymphocyte analysis at the time of diagnosis could clarify the role of lymphopenia in PTCL-NOS. Although IPI scores showed a significant role for predicting survival, ALC-a simple and easily obtainable test-was also found to have an independent role in predicting survival of patients with PTCL-NOS. Therefore, a lymphocyte count should be recommended as a standard test before initiation of first-line chemotherapy for PTCL-NOS.

Our study has some limitations. Because this study was conducted retrospectively, treatment regimens were not identical. To overcome this problem, we enrolled a relatively large number of patients newly diagnosed with PTCL-NOS who were treated with anthracycline-containing chemotherapy as first-line treatment. In this regard, large-scale, prospective studies are required to confirm the prognostic value of lymphopenia compared to other biologic tests, such as immunophenotyping or gene expression profiling. In addition, we did not perform a review of the pathology of each case, since cases had already been reviewed by experienced hematopathologists from each institution.

In conclusion, we found that lymphopenia was an independent prognostic factor for poor OS and PFS in patients with PTCL-NOS treated with anthracycline-containing chemotherapy. Lymphopenia was also a useful marker for further stratification of patients at high risk based on IPI scores. Further efforts to reduce TRM and new strategies to improve OS are needed, especially in patients with PTCL-NOS and lymphopenia.

\section{Acknowledgements}

This study was supported by a faculty research grant of Yonsei University College of Medicine for 2010 (6-2010-0065). Presented in abstract form at the $52^{\text {nd }}$ annual meeting of the American Society of Hematology, Orlando, FL, December 4-7, 2010

\section{Author details \\ 'Division of Hematology, Department of Internal Medicine, Yonsei University College of Medicine, Seoul, 120-752, Korea. 'Division of Hematology/ Oncology, Department of Medicine, Samsung Medical Center, Sungkyunkwan University School of Medicine, Seoul, 135-710, Korea. ${ }^{3}$ Hematology-Oncology Clinic, Center for Specific Organs Cancer, National Cancer Center, Goyang, 410-769, Korea. ${ }^{4}$ Department of Hematology- Oncology, Ajou University School of Medicine, Suwon, 443-749, Korea.}

\section{Authors' contributions}

YRK involved in conception, design, data interpretation, and manuscript writing. JSK performed data interpretation and revising it critically for intellectual content. SJK involved in acquisition of data, analysis of data. HAJ involved in acquisition of data, analysis of data. SJK involved in acquisition of data, analysis of data and participating in comprehensive discussion. WSK involved in analysis of data and participating in comprehensive discussion. HWL involved in acquisition of data, analysis of data. HSE involved in acquisition of data, analysis of data and participating in comprehensive discussion. SHJ involved in acquisition of data, analysis of data and participating in comprehensive discussion. JSP involved in acquisition of data, analysis of data and participating in comprehensive discussion. JWC involved analysis of data and participating in comprehensive discussion. YHM involved in analysis of data and participating in comprehensive discussion. All authors read and approved the final manuscript.

\section{Competing interests}

The authors declare that they have no competing interests.

Received: 30 July 2011 Accepted: 15 August 2011

Published: 15 August 2011

\section{References}

1. Savage KJ: Peripheral T-cell lymphomas. Blood reviews 2007, 21:201-216

2. Vose J, Armitage J, Weisenburger D: International peripheral T-cell and natural killer/T-cell lymphoma study: pathology findings and clinical outcomes. Journal of clinical oncology 2008, 26:4124-4130.

3. Agostinelli C, Piccaluga PP, Went P, Rossi M, Gazzola A, Righi S, Sista T, Campidelli C, Zinzani PL, Falini B, Pileri SA: Peripheral T cell lymphoma, not otherwise specified: the stuff of genes, dreams and therapies. Journal of Clinical Pathology 2008, 61:1160-1167.

4. Rizvi MA, Evens AM, Tallman MS, Nelson BP, Rosen ST: T-cell non-Hodgkin lymphoma. Blood 2006, 107:1255-1264.

5. Escaln MP, Liu NS, Yang Y, Hess M, Walker PL, Smith TL, Dang NH: Prognostic factors and treatment of patients with T-cell non-Hodgkin lymphoma: the M. D. Anderson Cancer Center experience. Cancer 2005, 103:2091-2098.

6. Gallamini A, Stelitano C, Calvi R, Bellei M, Mattei D, Vitolo U, Morabito F, Martelli M, Brusamolino E, lannitto E, et al: Peripheral T-cell lymphoma unspecified (PTCL-U): a new prognostic model from a retrospective multicentric clinical study. Blood 2004, 103:2474-2479.

7. Gutirrez-Garca G, Garca-Herrera A, Cardesa T, Martnez A, Villamor N, Ghita G, Martnez-Trillos A, Colomo L, Setoain X, Rodrguez S, et al: Comparison of four prognostic scores in peripheral T-cell lymphoma. Annals of oncology 2011, 22:397-404.

8. Vose JM: International Peripheral T-Cell Lymphoma (PTCL) Clinical and Pathologic Review Project: Poor Outcome by Prognostic Indices and Lack of Efficacy with Anthracyclines. Blood 2005, 106:811a.

9. A predictive model for aggressive non-Hodgkin's lymphoma. The International Non-Hodgkin's Lymphoma Prognostic Factors Project. The New England journal of medicine 1993, 329:987-994.

10. Martinez Delgado B, Melndez B, Cuadros M, Alvarez J, Castrillo JM, Ruiz De La Parte A, Mollejo M, Bellas C, Diaz R, Lombarda L, et al: Expression profiling of T-cell lymphomas differentiates peripheral and lymphoblastic lymphomas and defines survival related genes. Clinical cancer research 2004, 10:4971-4982.

11. Martnez-Delgado B, Cuadros M, Honrado E, Ruiz de la Parte A, Roncador G, Alves J, Castrillo JM, Rivas C, Bentez J: Differential expression of NFkappaB pathway genes among peripheral T-cell lymphomas. Leukemia 2005, 19:2254-2263.

12. Rodrguez-Antona C, Leskel S, Zajac M, Cuadros M, Alvs J, Moneo MV, Martn C, Cigudosa JC, Carnero A, Robledo M, et al: Expression of CYP3A4 as a predictor of response to chemotherapy in peripheral T-cell lymphomas. Blood 2007, 110:3345-3351.

13. Cox MC, Nofroni I, Laverde G, Ferrari A, Amodeo R, Tatarelli C, Saltarelli F, Veggia B, Aloe-Spiriti MA, Ruco L, Monarca B: Absolute lymphocyte count is a prognostic factor in diffuse large B-cell lymphoma. British journal of haematology 2008, 141:265-268.

14. Cox MC, Nofroni I, Ruco L, Amodeo R, Ferrari A, La Verde G, Cardelli P, Montefusco E, Conte E, Monarca B, Aloe-Spiriti MA: Low absolute lymphocyte count is a poor prognostic factor in diffuse-large-B-celllymphoma. Leukemia \& lymphoma 2008, 49:1745-1751.

15. Oki $Y$, Yamamoto $K$, Kato $H$, Kuwatsuka $Y$, Taji $H$, Kagami $Y$, Morishima $Y$ : Low absolute lymphocyte count is a poor prognostic marker in patients with diffuse large B-cell lymphoma and suggests patients' survival benefit from rituximab. European journal of haematology 2008, 81:448-453.

16. Kim DH, Baek JH, Chae YS, Kim YK, Kim HJ, Park YH, Song HS, Chung JS, Hyun MS, Sohn SK: Absolute lymphocyte counts predicts response to chemotherapy and survival in diffuse large B-cell lymphoma. Leukemia 2007, 21:2227-2230.

17. Behl D, Ristow K, Markovic SN, Witzig TE, Habermann TM, Colgan JP, Inwards DJ, White WL, Ansell SM, Micallef IN, et al: Absolute lymphocyte count predicts therapeutic efficacy of rituximab therapy in follicular lymphomas. British journal of haematology 2007, 137:409-415.

18. Ray-Coquard I, Cropet C, Van Glabbeke M, Sebban C, Le Cesne A, Judson I, Tredan O, Verweij J, Biron P, Labidi I, et al: Lymphopenia as a prognostic 
factor for overall survival in advanced carcinomas, sarcomas, and lymphomas. Cancer research 2009, 69:5383-5391.

19. Hasenclever D, Diehl V: A prognostic score for advanced Hodgkin's disease. International Prognostic Factors Project on Advanced Hodgkin's Disease. The New England journal of medicine 1998, 339:1506-1514.

20. Porrata LF, Rsitow K, Inwards DJ, Ansell SM, Micallef IN, Johnston PB, Habermann TM, Witzig TE, Colgan JP, Nowakowski GS, et al: Lymphopenia assessed during routine follow-up after immunochemotherapy (R-CHOP) is a risk factor for predicting relapse in patients with diffuse large B-cell lymphoma. Leukemia 2010, 24:1343-1349.

21. Porrata LF, Ristow K, Habermann TM, Witzig TE, Inwards DJ, Markovic SN: Absolute lymphocyte count at the time of first relapse predicts survival in patients with diffuse large B-cell lymphoma. American journal of hematology 2009, 84:93-97.

22. Huang JJ, Jiang $W Q$, Lin TY, Huang $Y, X u R H$, Huang HQ, Li ZM: Absolute lymphocyte count is a novel prognostic indicator in extranodal natural killer/T-cell lymphoma, nasal type. Annals of oncology 2011, 22:149-155.

23. Cheson BD, Horning SJ, Coiffier B, Shipp MA, Fisher RI, Connors JM, Lister TA, Vose J, Grillo-Lpez A, Hagenbeek A, et al: Report of an international workshop to standardize response criteria for nonHodgkin's lymphomas. NCl Sponsored International Working Group. Journal of clinical oncology 1999, 17:1244-1244.

24. Weisenburger D, Savage KJ, Harris NL, Gascoyne RD, Jaffe ES, Maclennan KA, Rdiger T, Pileri S, Nakamura S, Nathwani B, et al: Peripheral T-cell lymphoma, not otherwise specified: a report of 340 cases from the International Peripheral T-cell Lymphoma Project. Blood 2011 117:3402-3408

25. Castillo J, Morales D, Quinones P, Cotrina E, Desposorio C, Beltran B: Lymphopenia as a prognostic factor in patients with peripheral T-cell lymphoma, unspecified. Leukemia \& lymphoma 2010, 51:1822-1828.

26. Kao SC, Pavlakis N, Harvie R, Vardy JL, Boyer MJ, van Zandwijk N, Clarke SJ: High blood neutrophil-to-lymphocyte ratio is an indicator of poor prognosis in malignant mesothelioma patients undergoing systemic therapy. Clinical cancer research 2010, 16:5805-5813.

27. Porta C, Larghi P, Rimoldi M, Totaro MG, Allavena P, Mantovani A, Sica A: Cellular and molecular pathways linking inflammation and cancer. Immunobiology 2009, 214:761-777.

28. Plonquet A, Haioun C, Jais JP, Debard AL, Salles G, Bene MC, Feugier P, Rabian C, Casasnovas O, Labalette M, et al: Peripheral blood natural killer cell count is associated with clinical outcome in patients with aalPI 2-3 diffuse large B-cell lymphoma. Annals of oncology 2007, 18:1209-1215.

29. Borg C, Ray Coquard I, Philip I, Clapisson G, Bendriss Vermare N, Menetrier Caux C, Sebban C, Biron P, Blay J: CD4 lymphopenia as a risk factor for febrile neutropenia and early death after cytotoxic chemotherapy in adult patients with cancer. Cancer 2004, 101:2675-2680.

doi:10.1186/1756-8722-4-34

Cite this article as: Kim et al:: Lymphopenia is an important prognostic factor in peripheral T-cell lymphoma (NOS) treated with anthracyclinecontaining chemotherapy. Journal of Hematology \& Oncology 2011 4:34.

\section{Submit your next manuscript to BioMed Central and take full advantage of:}

- Convenient online submission

- Thorough peer review

- No space constraints or color figure charges

- Immediate publication on acceptance

- Inclusion in PubMed, CAS, Scopus and Google Scholar

- Research which is freely available for redistribution 